\title{
Microgrid Optimum Identification Location Based on Accelerated Particle Swarm Optimization Techniques Using SCADA System
}

\author{
Samir Abood ${ }^{*}$, Warsame Ali ${ }^{1}$, John Attia', Pamela Obiomon', Muna Fayyadh ${ }^{2}$ \\ ${ }^{1}$ Department of Electrical and Computer Engineering, Prairie View A \& M University, Prairie View, USA \\ ${ }^{2}$ American InterContinental University-Houston, Houston, USA \\ Email: ^sabood@pvamu.edu,whali@pvamu.edu, joattia@pvamu.edu,pobiomon@pvamu.edu, mfayyadh@aiuniv.edu
}

How to cite this paper: Abood, S., Ali, W., Attia, J., Obiomon, P. and Fayyadh, M. (2021) Microgrid Optimum Identification Location Based on Accelerated Particle Swarm Optimization Techniques Using SCADA System. Journal of Power and Energy Engineering, 9, 10-28.

https://doi.org/10.4236/jpee.2021.97002

Received: June 2, 2021

Accepted: July 16, 2021

Published: July 19, 2021

Copyright $\odot 2021$ by author(s) and Scientific Research Publishing Inc. This work is licensed under the Creative Commons Attribution International License (CC BY 4.0).

http://creativecommons.org/licenses/by/4.0/

\begin{abstract}
The microgrid has become significant and commonly used; it has localized electricity sources and loads connected to a centralized electrical power network system when the need arises and disconnects to island mode. A microgrid can effectively be integrated with various distribution generators, which can improve the voltage level on the transmission line by reducing the real power losses. In this work, new technologies will permit power grids to be better prepared for future requirements. The numbers and diversity of such decentralized power plants require a new type of management in the operation of power grids and intelligent networks or "smart grid." A SCADA system will improve coordination between power demand and generation and use of modern information technology such as the internet, sensors, controllers, and wireless transmission equipment and use smart metering. The Accelerated Particle Swarm Optimization technique will be used to select the optimum location of a wind turbine to install in the power grid considering minimum power losses with optimal operation consideration of the number of iterations, the execution time of the program, and the memory capacity. The analysis and the study are carried out in MATLAB and the SCADA system.
\end{abstract}

\section{Keywords}

APSO, SCADA Power System, Accelerated PSO

\section{Introduction}

A microgrid is an isolated power system that can manage intelligent distribution power resources, interconnected loads and work in parallel with or independently of the network. In the same mood, electric power can be provided eco- 
nomically while enhancing energy quality and reliability by integrating and improving energy sources. However, the validity of a microgrid network depends on the combination of power sources, size or capacity allocated, and the transmission strategy [1]. Wind energy is a promising technology commonly used in microgrid networks [2] [3] since winds are a clean energy source that is available everywhere and is available free of charge. Still, it depends to a great extent on on-site meteorology [4].

To minimize the loss, a microgrid site has a key role. The losses are reduced to a minimum amount by increasing the installed generator's size [5] [6]. The selection of the suitable site of distributed generators in the system also plays a leading role in reducing the active power losses [7], interactive and interactive. In this work, many investigations have different future methods to minimize losses of the system. A Distribution Generator (D.G.) can also reduce the cost of the network upgrade. However, if the location of the distribution generator is not realistic, on the conflicting, may lead to an increased energy loss, so the preparation and scaling distribution generator in The previous size depends on the minimum transmission loss; Send traditional power system, power transmission distribution is managed together, there is no need to compute the cost of losses in each part [8].

The main features affecting the cost of energy transfer losses are transmission line losses and the generating price. In this situation from the specified energy flow, all generations prices are the same in the traditional power grid, so, the minimum loss of transmission line means almost The minimum cost of transmission losses, but the cost of generating D.G. is much higher than traditional generations, location D.G. measurement may only consider the loss of transmission to increase the transmission cost in the power grid layout, the calculations are optimized with the cost of transmission loss goal function is necessary [9].

In this work, we proposed a schematic for the loss reduction system; the 4-step loss reduction plan, as described below, includes divided into sections, including analysis of the load flow, acquisition of the voltage profile, control and reduction of losses, and optimization using an approach based on two algorithms are obtained for the placement of D.G., the PSO, and APSO, and monitor the data profile [10]. Finally, the aim of this work is summarized in the Modeling, design, and implementation of optimum operation perform for the smart grid to high-quality performance using a SCADA system.

\section{Optimum Location of Distribution Generator}

The optimization of the distribution network is mainly from an economic point of view. However, single-objective optimization will ignore the interests of other aspects, and different factors need to be considered in D.G. investment subjects' decisions. The power region or D.G. investors are more eager to get the maximum benefits. They pay more attention to the investment cost of D.G. As users, they hope to obtain safe and stable electricity, mainly focusing on the quality of 
power. It can be seen that under the various requirements of power network operation quality and economic benefits, the future direction of reactive power optimization is to comprehensively consider the economy, safety, and power supply reliability of power system operation [11] [12], so it is necessary to establish a multi-objective reactive power optimization model to meet the needs of multiple parties.

The control system in standalone micro-grid is under severe compulsion to 1) achieve demand-supply equilibrium in all conditions; 2) control and restore the system frequency and bus voltages to their nominal values whenever a disturbance has happened [13]. The latest trend in standalone micro-grid control is to provide a primary reserve for each D.G. unit, whether it is dispatchable or nondispatchable. By doing so, every D.G. can participate in frequency control apart from its local bus voltage control during transient conditions, although in the steady state only dispatchable units can account for the frequency restoration [14]. The conventional control system of the synchronous D.G. consists of the turbine reference set point control and excitation system control using P.I. Controllers.

\subsection{Accelerating Particle Swarm Optimization Technique (APSO)}

Article movement factors consist of two main components: an inevitable element and a random component. Each particle is attracted to the best current position $G$ and the best $X_{i}^{*}$ Site in history, while at the same time tends to transfer arbitrarily. For example, let be the vector location $x_{i}$ and the particles velocity $V_{i}$ of $i$, respectively, so the following formula calculates the new speed transducer [14]:

When required, the diversity in quality solutions increase, improving the standard PSO uses the best position individual $X_{i}^{*}$, and the global best $g^{*}$ [15]. The difference can be simulated by using randomization for using the best individual is mainly. Later, there is no convincingly motive to use the best individuals, except the problem optimization is multimodal and extremely nonlinear [16]. A basic model that can accelerate the meeting of the procedure is to use the globally better only. Thus, in this way of the acceleration of particle swarm optimization [17] [18], the velocity vector is generated by the Equation:

$$
v_{i}^{t+1}=v_{i}^{t}+\alpha \epsilon_{n}+\beta\left[g^{*}-X_{i}^{t}\right]
$$

where: $\epsilon_{n}$ is outgoing $N(0,1)$ to replace the next term. To increase the convergence more, we can also write the location update in one step:

$$
x_{i}^{t+1}=(1-\beta) x_{i}^{t}+\alpha \epsilon_{n}+\beta g^{*}
$$

Usually, $\alpha=0.1 K$ to $0.5 K$, where $K$ is the measure of each variable and $\beta$ selects from 0.1 to 0.7 for suitable in most applications. There is no requirement to accord with the vectors of velocity formation, so be noted that speed does not appear in Equation (5); therefore, APSO is much simpler, and the mechanism is easy to understand. Compared with many standard PSO variables, the APSO 
uses two exclusive parameters; another improvement in the accelerated PSO system is to reduce randomization while duplicates persist. This means that we can use a monotonous decrease function like:

$$
\alpha=\alpha_{0} \cdot \exp [-\gamma t]
$$

or,

$$
\alpha=\alpha_{0} \cdot \gamma^{t},(0<\gamma<1)
$$

where: $\alpha_{0}$, approximately from 0.5 to 1 , is the initial value of the random parameter. Here $t$ is the number of duplicates or time steps, and $\gamma$ is a control parameter [19]. For example, in this application, we will use:

$$
\alpha=0.75 \cdot t
$$

where: $t \in\left[0\right.$ and $t_{\max }$ ] and $t_{\max }$ is the maximum iteration [20].

\subsection{Objective Function}

In the power systems, the dispatch of reactive electricity power may have different goals, such as obtaining the best voltage quality and reducing real power losses. Considered the voltage magnitude is $\left|V_{i}\right|$ and $\left|V_{j}\right|$ at buses $i$ and $j$, respectively so, the power loss as an objective function and described by the formula [21]:

$$
f: P_{\text {loss }}=\sum_{K=1}^{M} g_{i j}\left(\left|V_{i}\right|^{2}+\left|V_{j}\right|^{2}-2\left|V_{i}\right|\left|V_{j}\right| \cdot \cos \theta_{i j}\right)
$$

$M$ is the number of branches, while the angle $\theta_{i j}$ is the difference in the phase of voltage angle at bus $i$ and bus $j$, respectively, and $g_{i j}$ represents the branch conductance of impedance between the buses $i$ and $j$ [22].

\subsection{Constraints}

There are two constraints dispatch issue of reactive power, equality, and inequality constraints as follows:

1) Equality Constraint: If we suppose the real and imaginary power supplying to bus $i$ are $P_{g i}$ and $Q_{g j}$ respectively, and the real and imaginary demand load power at bus $i$ are $P_{d i}$ and $Q_{d i}$ respectively, so The real and imagery power is given by the following formulas [23]:

$$
\begin{aligned}
& y_{1}: P_{g i}-P_{d i}-V_{i} \sum V_{j}\left(G_{i j} \cos \theta_{i j}+B_{i j} \sin \theta_{i j}\right)=0 \\
& y_{2}: Q_{g i}-Q_{d i}-V_{i} \sum V_{j}\left(G_{i j} \sin \theta_{i j}-B_{i j} \cos \theta_{i j}\right)=0
\end{aligned}
$$

2) Inequality Constraint: It's the voltage magnitude range value, tap changing transformer positions value, and injection reactive power to the system. In this paper, and based upon the IEEE 30-bus system's data, the voltage magnitude values are selected from 0.950 p.u to 1.10 p.u, and the tap changing transformer range is usually from 0.975 to 1.025 . The compensator's injection of reactive power to the system from 0 MVAR to 20 MVAR. The Inequality Constraint is given by the following relations [20] [24]:

$$
g_{1}: V_{i}^{\min }<V_{i}<V_{i}^{\max }
$$




$$
\begin{gathered}
g_{2}: t_{j}^{\min }<t_{j}<t_{j}^{\max } \\
g_{3}: Q_{g i}^{\min }<Q_{g i}<Q_{g i}^{\max }
\end{gathered}
$$

So, the objective function given in equation nine can be expressed by follows:

$$
F=P_{\text {loss }}+\sum r_{g i} \cdot\left(V_{i}-V_{i}^{\lim }\right)^{2}+\sum r_{t i} \cdot\left(T_{i}-T_{i}^{\lim }\right)+\sum r_{Q i} \cdot\left(Q_{i}-Q_{i}^{\lim }\right)^{2}
$$

And the values of voltage magnitude, tap changing transformer, and injection reactive power described as follows [25] [26]:

$$
\begin{aligned}
& V_{i}^{\lim }=\left\{\begin{array}{l}
V_{i}^{\max } ; V_{i}>V_{i}^{\max } \\
V_{i}^{\min } ; V_{i}<V_{i}^{\min }
\end{array}\right. \\
& T_{i}^{\lim }=\left\{\begin{array}{l}
T_{i}^{\max } ; T_{i}>T_{i}^{\max } \\
T_{i}^{\min } ; T_{i}<T_{i}^{\min }
\end{array}\right. \\
& Q_{i}^{\lim }=\left\{\begin{array}{l}
Q_{i}^{\max } ; Q_{i}>Q_{i}^{\max } \\
Q_{i}^{\min } ; Q_{i}<Q_{i}^{\min }
\end{array}\right.
\end{aligned}
$$

\section{Systems Understudy}

This work examines the possibility of using wind power energy for electricity generation at optimum conditions and a simulation network for IEEE 3 buses. A MATLAB program was used to analyze the system; they allow comparison with different design options.

The proposed technique is performed and verified on the IEEE busbar network for three buses system. The power system network construction is indicated in Figure 1.

\subsection{Modelling of Wind Power}

The Wind Power depends on [27]:

- amount of air (volume);

- speed of air (velocity);

- mass of air (density) $A$.

flowing through the area of interest (flux).

The Kinetic Energy definition as:

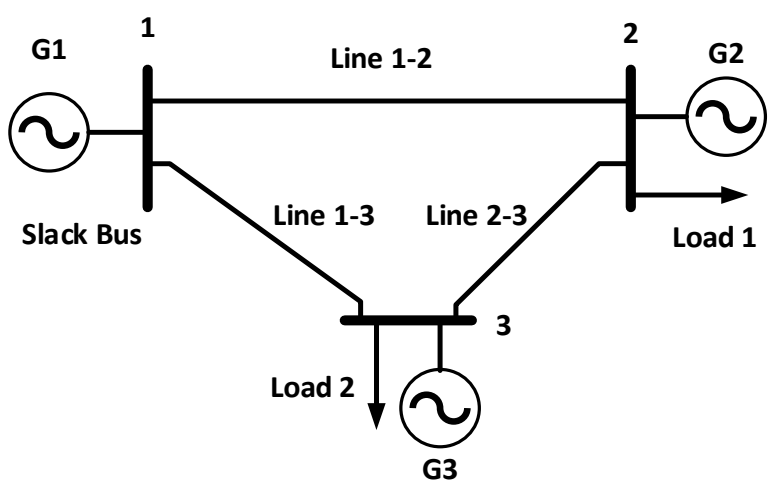

Figure 1. The IEEE 3 bus system. 


$$
\text { Kinetic Energy } \mathrm{KE}=\frac{1}{2} \cdot m \cdot v^{2}
$$

The Power is K.E. per unit time [28]:

$$
P=\frac{1}{2} \cdot \dot{m} \cdot v^{2}
$$

where $\dot{m}$ is the mass flux and given by:

$$
\dot{m}=\frac{\mathrm{d} m}{\mathrm{~d} t}
$$

Fluid mechanics gives the mass flow rate,

$$
\frac{\mathrm{d} m}{\mathrm{~d} t}=\rho \cdot A \cdot v
$$

Thus,

$$
P=\frac{1}{2} \cdot \rho \cdot A \cdot v^{3}
$$

where $\rho$ is the air density.

$$
A=\pi \cdot r^{2}
$$

- Therefore, the power proportional to air density, rotor swept area and the velocity cube.

\subsection{Efficiency in Extracting Wind Power (Betz Limit \& Power Coefficient)}

Power Coefficient, $C_{p}$, is the ratio of power extracted by the turbine to the total contained in the wind resource [28],

$$
C_{p}=\frac{P_{T}}{P_{W}}
$$

- Turbine power output,

$$
P_{T}=\frac{1}{2} \cdot \rho \cdot A \cdot v^{3} \cdot C_{p}
$$

The Betz Limit is the maximal possible $C_{p}=16 / 27$. Thus, $59 \%$ efficiency is the BEST a conventional wind turbine can do in extracting power from the wind [29].

\subsection{Power Curve of Wind Turbine}

Capacity Factor (C.F.): The fraction of the year the turbine generator is operating at rated (peak) power [30].

$$
\text { Capacity Factor }(\mathrm{CF})=\frac{\text { Average Output }}{\text { Peak Output }} \approx 30 \%
$$

C.F. is based on both the characteristics of the turbine and the site characteristics (typically 0.3 or above for a good site) ENERCON wind energy converters run with a particular storm control feature. An E-82 ENERCON wind energy converters as D.G. with 2.05 MW rated power. Figure 2 illustrates Power-Wind 


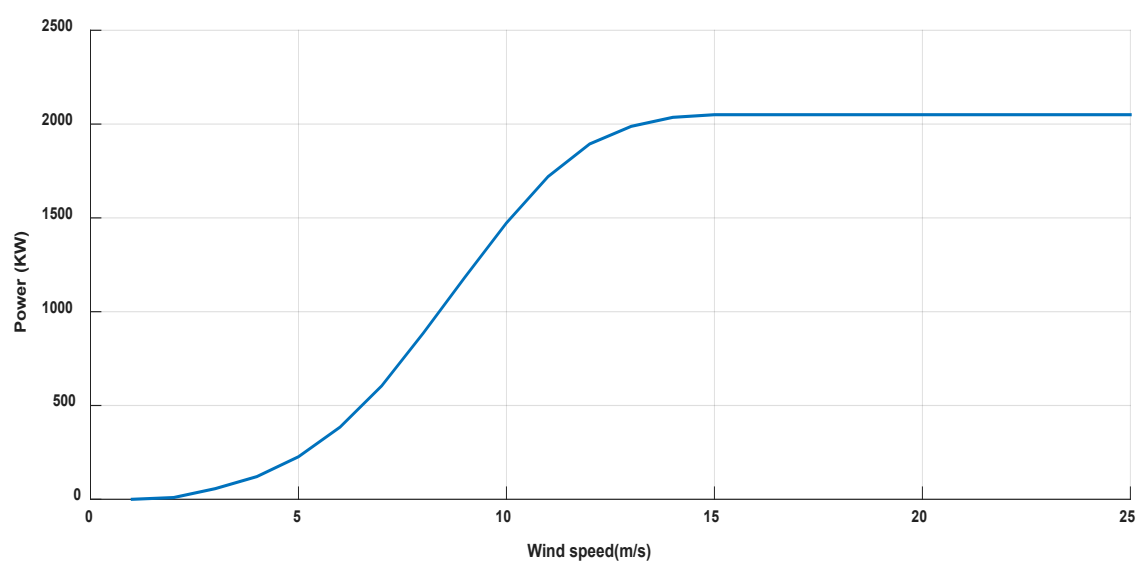

Figure 2. Power-wind speed characteristics [31].

speed characteristics for $2.05 \mathrm{MW} / \mathrm{E}-82$ ENERCON wind energy converters, while Figure 3 shows the characteristics of Power Coefficient-Wind speed for its [29] [30] [31].

\subsection{Selection Particles of APSO}

In this work, the particle selected in each technique as the voltage magnitude at slack bus and each $\mathrm{P}|\mathrm{V}|$ generation bus also taps changing transformer ratio and the injected reactive power to the system. There are three particles: (|V1|, |V2|, and $|\mathrm{V} 3|)$ no tap changing transformer ratio and no injected reactive power at buses. When the optimization development process begins, each particle position will continuously update until they reach the stop criteria. The minimum inertia weight is selected as 0.45 , and the maximum weight limitations are chosen as 0.95 . With continuous repetition, the weight value will drop from 0.95 to 0.45 .

\section{Smart Grids with a Scada System}

This section imparts a general practical knowledge of smart grids with the SCADA system applied in this paper. Providing shifts in household consumption away from peak load periods and running flexible applications such as air conditioning directly by power supply companies outside peak load periods. The main equipment used in this work as:

1) Fundamentals of electrical engineering;

2) Complex A.C. technology;

3) Three-phase technology;

4) Measurement technology;

5) Power transmission;

6) Line protection;

7) Power distribution;

8) Power management.

A three-phase power with conductor currents of up to $3 \times 5$ A can be conveyed, measured, and switched via the double busbar model. Also, the board is a 


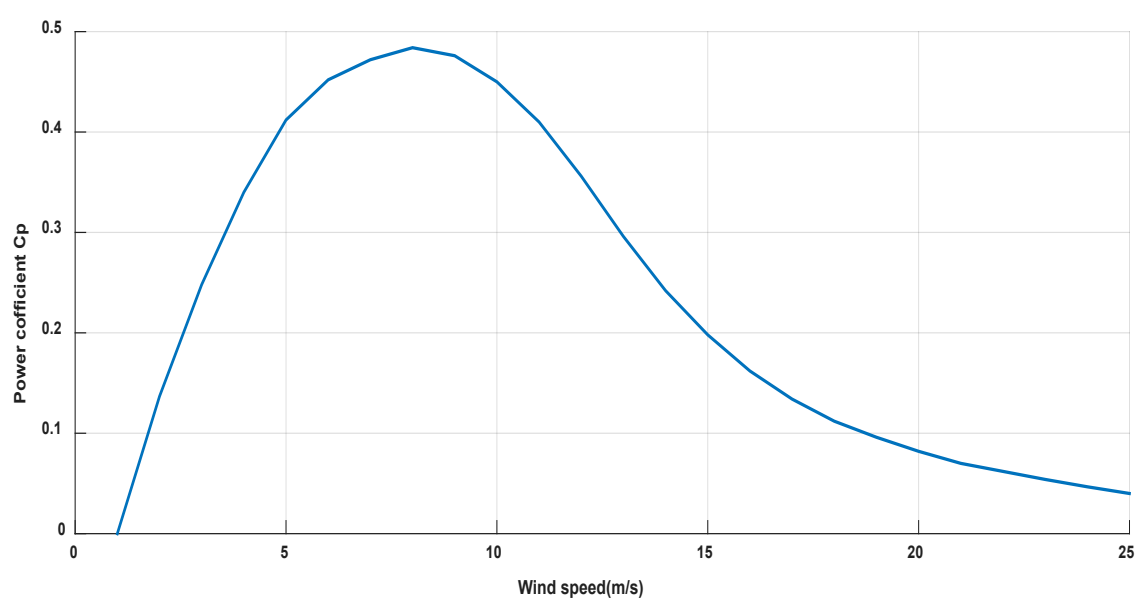

Figure 3. Power coefficient-wind speed characteristics [31].

branch/connector, which can be turned on and off via isolators. The subsequent circuit breaker also has a three-phase design and switches the outgoing and incoming power feeders on and off and change busbars.

The isolators and circuit breakers are controlled manually using pushbuttons or using a remote switching device (e.g., PLC, protective relay) via a control input. In addition, the isolators and circuit breakers are equipped with an auxiliary contact via which indicator lights and other signaling devices can be switched. LEDs indicate the switching status. Overcurrent is also indicated by an LED and opens the switches.

Certain switching combinations are interlocked more on this later. Incorrect operations of this kind are signaled visually and acoustically by the models.

Switching can be performed in three different ways:

1) Manually on the device using on/off buttons.

2) Via digital control voltage inputs (max. $30 \mathrm{~V} D C$ ).

3) Via Ethernet using SCADA system Designer/Viewer.

The modules can be interconnected via the RS485 port and operated via SCADA system Viewer/Designer.

\subsection{SCADA Connection Hardware}

Before using the SCADA system for the first time, we should make a one-time hardware connection for mutual communication. In some cases, the various devices are connected via different interfaces to the P.C. The configuration for each type of connection is described in the corresponding section of this topic.

\subsection{Connection via Ethernet}

The following installation instructions explain how to connect devices to the SCADA system via Ethernet. This is important when using a SCADA control computer with network access, the double busbars CO3301-5R/CO3301-5S, and other supported equipment such as the power quality meter CO5127-1S the human-machine interface (HMI) CO3301-5L. 
To establish a structured hierarchy of I.P. addresses assigned to each Table or set of equipment. This makes subsequent setting up much easier.

\subsection{Configuration of IP Address for Scada Control Computer}

For the I.P. address of the P.C. could use 192.168.168.1, for example, as in Figure 4, with a subnet mask of 255.255.255.0, in this network, then have the addresses 192.168.168.1 to 192.168.168.254 (excluding the P.C.'s I.P. address) available for other equipment.

The SCADA Viewer/Designer now searches the double busbars using all the ports on the computer. The computer and the device to be connected do not have to be configured for a common sub-network, as shown in Figure 5, control of double busbars via SCADA, details of busbars via SCADA.

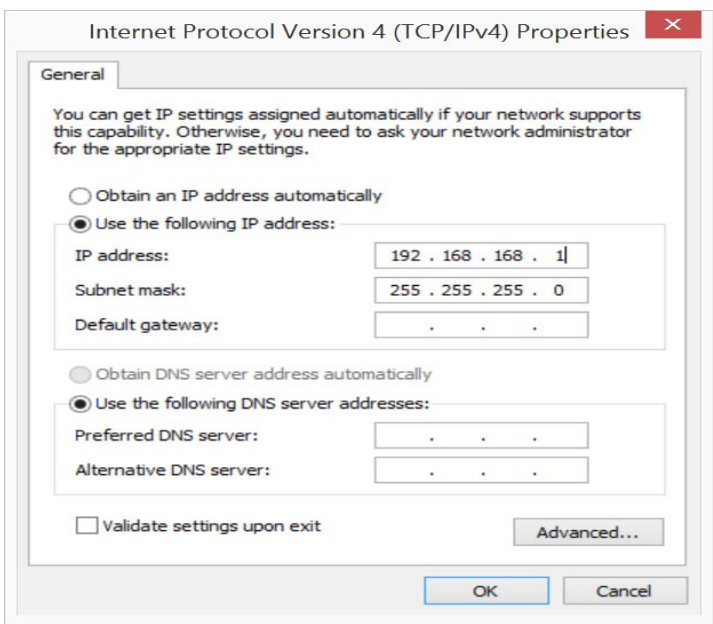

Figure 4. Assigning a fixed I.P. address.

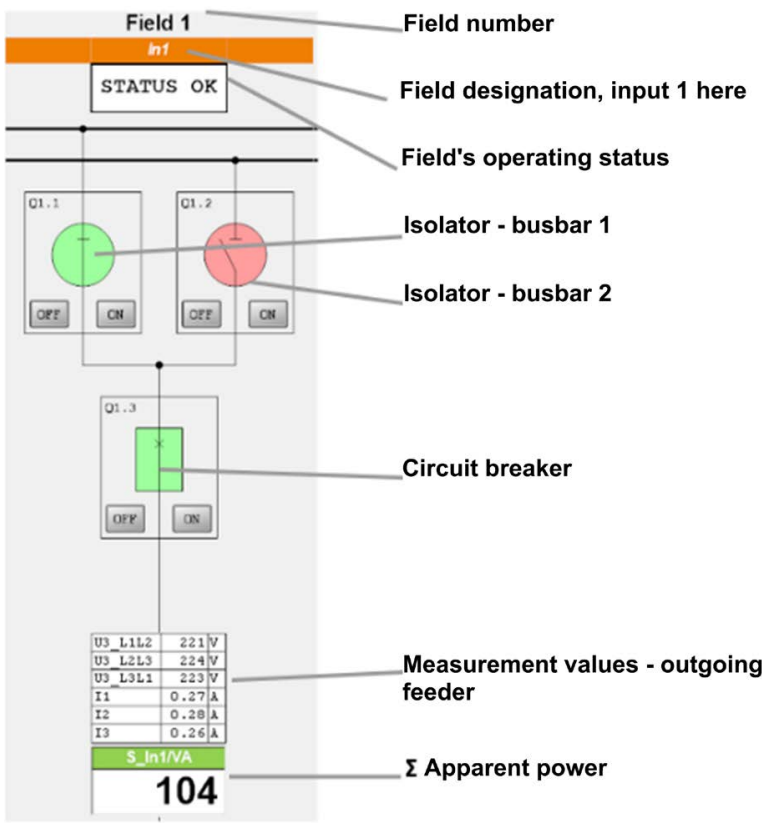

Figure 5. Details of busbars via SCADA system. 
Busbar 1;

Busbar 2;

Control panel for isolator Q1;

Control panel for isolator Q2;

Control panel for circuit breaker Q3;

Ethernet connections for measurement and control;

$0 \mathrm{~V}$ control voltage connection (not a neutral conductor!);

$400 \mathrm{~V}$ incoming/outgoing busbar feeder.

\subsection{Configuration of the SCADA Interface}

This work setup permits any required combination of energy sources and consumers to study smart grids' basic relationships. The voltages and currents are evaluated using the SCADA for Power Lab software converter. Figure 6 shows a basic setup of the ESG 1.1 training station.

\section{Simulation Results and Discussion}

The practical work is to select the optimum location of the distribution generator on the power system. A three-bus system tested using the Supervisory Control and Data Acquisition (SCADA) program to compare APSO results. The algorithm is done by using APSO by MATLAB.

A three-bus test system was applied to test the optimum power flow and compare the APSO and hand calculation results. The test power system shown in Figure 1 contains three feeders, three generators, three transmission lines, two loads first one resistive, and the second load is inductive. The data of the power system is given in Tables 1-3 shows the load data. The per-unit values are

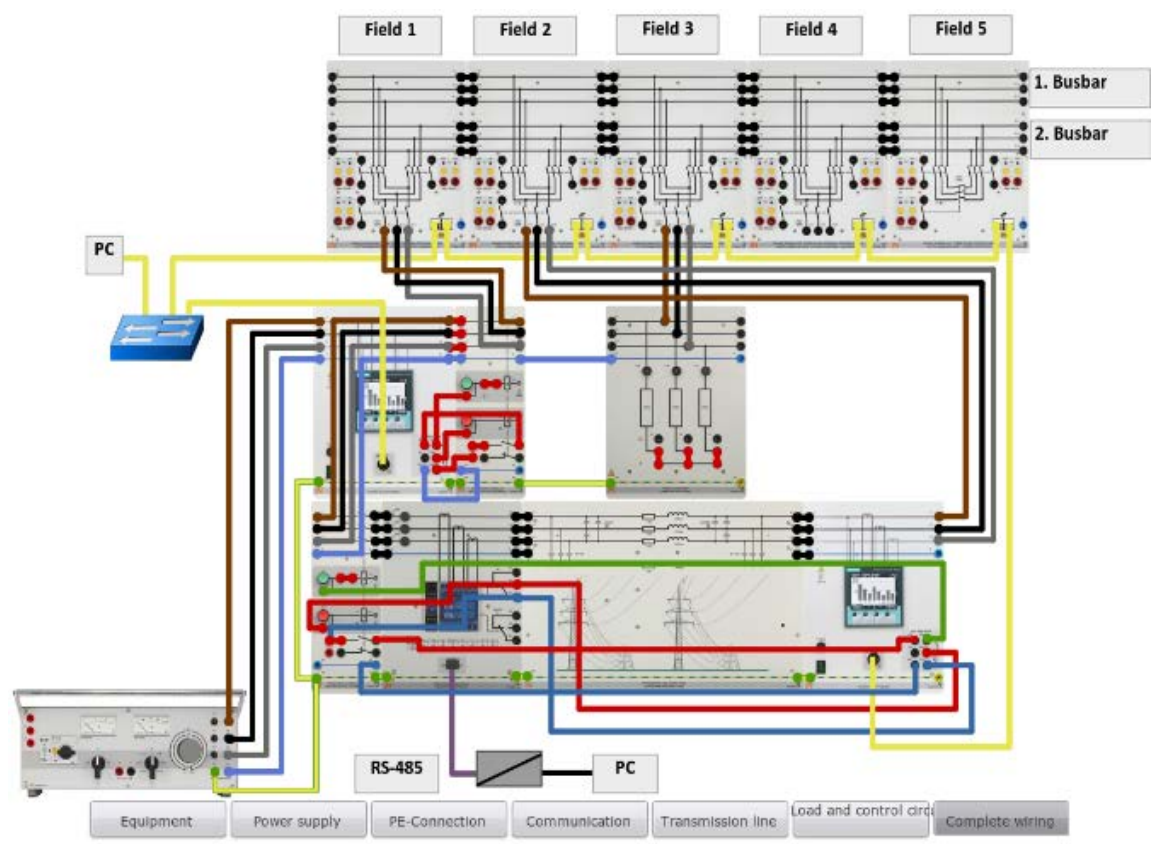

Figure 6. Basic setup of the ESG 1.1 training station. 
Table 1. Bus data three bus test system used.

\begin{tabular}{|c|c|c|c|c|c|c|c|c|c|}
\hline \multirow{2}{*}{$\begin{array}{l}\text { Bus } \\
\text { No. }\end{array}$} & \multirow{2}{*}{ Type } & \multirow{2}{*}{$\begin{array}{c}|V| \\
\text { (p.u) }\end{array}$} & \multirow{2}{*}{$\begin{array}{c}\delta \\
\text { (Degree) }\end{array}$} & \multirow{2}{*}{$\begin{array}{r}V_{\text {actual }} \\
\text { (Volt) }\end{array}$} & \multirow{2}{*}{$\begin{array}{c}V_{\text {base }} \\
\text { (Volt) }\end{array}$} & \multicolumn{2}{|c|}{ Generation } & \multicolumn{2}{|c|}{ Load } \\
\hline & & & & & & $P(\mathrm{~W})$ & $Q(\mathrm{VAR})$ & $P(\mathrm{~W})$ & $Q(\mathrm{VAR})$ \\
\hline 1 & Slack & 1.01667 & 0 & 244 & 240 & 100 & - & 0 & 0 \\
\hline 2 & $P \mid \eta$ & 1.0 & 0 & 240 & 240 & 104.79 & - & 56 & 35 \\
\hline 3 & $P|V|$ & 1.0 & 0 & 240 & 240 & 155.73 & - & 106 & 0 \\
\hline
\end{tabular}

Table 2. Transmission line data three bus test system used.

\begin{tabular}{cccccccc}
\hline From bus & To bus & $R(\Omega)$ & $X(\Omega)$ & $B\left(\Omega^{-1}\right)$ & $R(\mathrm{p} . \mathrm{u})$ & $X(\mathrm{p} . \mathrm{u})$ & $B(\mathrm{p} . \mathrm{u})$ \\
\hline 1 & 2 & 7.2 & 86.7 & $1.13 \times 10^{-4}$ & 0.2922 & 3.52 & $2.78 \times 10^{-3}$ \\
1 & 3 & 0.75 & 7.07 & $2.26 \times 10^{-3}$ & 0.0304 & 0.287 & 0.05571 \\
2 & 3 & 7.2 & 86.7 & $1.13 \times 10^{-4}$ & 0.2922 & 3.52 & $2.78^{\star} 10^{-3}$ \\
\hline
\end{tabular}

Table 3. Load data three bus test system used.

\begin{tabular}{cccccc}
\hline Load No. & Bus No. & $R(\Omega)$ & $X(\Omega)$ & $R(\mathrm{p} . \mathrm{u})$ & $X(\mathrm{p} . \mathrm{u})$ \\
\hline 1 & 2 & 500 & 452.4 & 20 & 18.36 \\
2 & 3 & 750 & 0 & 23.14 & 0 \\
\hline
\end{tabular}

based on $2338.26 \mathrm{VA}$ and $249 \mathrm{~V}$, so the base impedance and current are $24.633 \Omega$ and $5.625 \mathrm{~A}$, respectively.

\subsection{Manual calculations}

The manual calculation used Fast Decoupled Load Flow to calculate the voltage at each bus, power flow, and power losses in each line. The bus admittance is given as:

$$
Y_{\text {bus }}=\left[\begin{array}{ccc}
0.388-j 3.698 & -0.02342+j 0.2821 & -0.365+j 3.445 \\
-0.02342+j 0.2821 & 0.04684-j 0.5615 & -0.02342+j 0.2821 \\
-0.365+j 3.445 & -0.02342+j 0.2821 & 0.3919-j 3.7178
\end{array}\right]
$$

The current flow to bus 2 is $0.25 \mathrm{~A}$, and bus 3 is $0.46 \mathrm{~A}$, respectively.

The power mismatch,

$$
\begin{gathered}
\Delta P_{2}=P_{2 \text { spec. }}-P_{2 \text { calc. }}=(0.0448-0.024)-0.044444=-0.0236 \mathrm{p} . \mathrm{u} \\
\Delta P_{3}=P_{3 \text { spec. }}-P_{3 \text { calc }}=(0.0666-0.0453)-0.08177=-0.06047 \mathrm{p} . \mathrm{u}
\end{gathered}
$$

and,

$$
\begin{gathered}
\Delta Q_{2}=Q_{2 \text { spec. }}-Q_{2 \text { calc }}=(0-0.015)-0=-0.015 \text { p.u } \\
{\left[\begin{array}{l}
\frac{\Delta P_{2}}{\left|V_{2}\right|} \\
\frac{\Delta P_{3}}{\left|V_{3}\right|}
\end{array}\right]=-\left[\begin{array}{ll}
B_{22} & B_{23} \\
B_{32} & B_{33}
\end{array}\right]\left[\begin{array}{l}
\Delta \delta_{2} \\
\Delta \delta_{3}
\end{array}\right]}
\end{gathered}
$$




$$
\begin{gathered}
{\left[\begin{array}{c}
\frac{-0.0236}{1.0} \\
\frac{-0.06047}{1.0}
\end{array}\right]=-\left[\begin{array}{ll}
-0.5615 & 0.28121 \\
0.28121 & -3.7178
\end{array}\right]\left[\begin{array}{l}
\Delta \delta_{2} \\
\Delta \delta_{3}
\end{array}\right]} \\
{\left[\begin{array}{c}
\Delta \delta_{2} \\
\Delta \delta_{3}
\end{array}\right]=\left[\begin{array}{cc}
0.5615 & -0.28121 \\
-0.28121 & 3.7178
\end{array}\right]^{-1}\left[\begin{array}{c}
-0.0236 \\
-0.06047
\end{array}\right]} \\
{\left[\begin{array}{c}
\Delta \delta_{2} \\
\Delta \delta_{3}
\end{array}\right]=\left[\begin{array}{c}
-0.052184 \\
-0.02
\end{array}\right] \mathrm{rad}=\left[\begin{array}{l}
-2.9899 \\
-1.1459
\end{array}\right] \text { degree }} \\
{\left[\frac{\Delta Q_{2}}{\left|V_{2}\right|}\right]=-\left[B_{22}\right]\left[\Delta\left|V_{2}\right|\right]} \\
{\left[\frac{-0.015}{1.0}\right]=-[-0.5615]\left[\Delta\left|V_{2}\right|\right]} \\
{\left[\Delta\left|V_{2}\right|\right]=-0.0267 \mathrm{p.u}} \\
\left|V_{2}\right|=1.0-0.0267=0.9733 \mathrm{p} . \mathrm{u}
\end{gathered}
$$

So, the voltage after the first iteration:

$$
\begin{gathered}
V_{2}^{(1)}=1.0 \angle-2.9899 \text { p.u And } \\
V_{3}^{(1)}=0.9733 \angle-1.1459 \text { p.u }
\end{gathered}
$$

\begin{tabular}{|c|c|c|c|c|}
\hline Branch \# & Before optimization & APSO By MATLAB (W) & Manual Calculations & SCADA Results \\
\hline $1-2$ & 2.33826 & 1.3232 & 1.2023 & 2.33826 \\
\hline $1-3$ & 23.3826 & 20.1236 & 20.1233 & 23.3826 \\
\hline $2-3$ & 2.33826 & 1.3232 & 1.2021 & 2.33826 \\
\hline Total & 28.05912 & 22.770 & 22.5277 & 28.0591 \\
\hline
\end{tabular}

After three iterations, the final results were the convergence of the value given in Table 4 for power losses in each branch for 3-busbar test system, and Table 5 shows the voltage profile for 3-busbar test system. The results in the tables show that they are almost close. Figure 7 shows a three-bus emulation system representation by SCADA, and Figure 8 shows a three-bus system result by SCADA for Line voltage and injected current at each busbar.

Table 4. Power losses in each branch.

Table 5. Voltage profile for 3-busbar system.

\begin{tabular}{ccccc}
\hline Bus \# & Without optimization & $\begin{array}{c}\text { optimization APSO } \\
\text { Without DG }\end{array}$ & Manual Calculations & SCADA Results \\
\hline 1 & 1.017 & 1.065 & 1.0167 & 1.017 \\
2 & 0.991 & 0.992 & 1.0 & 0.99 \\
3 & 0.981 & 0.987 & 0.987 & 0.981 \\
\hline
\end{tabular}




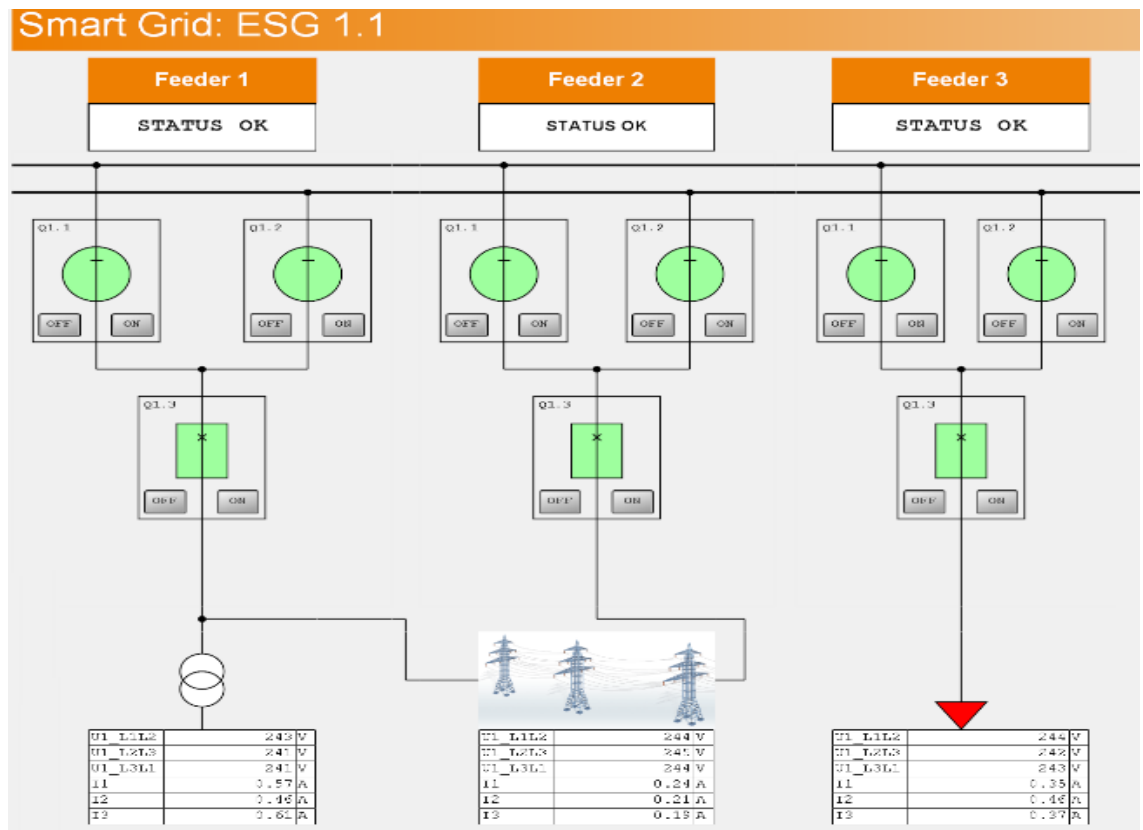

Figure 7. A three bus emulation system representation by SCADA system.

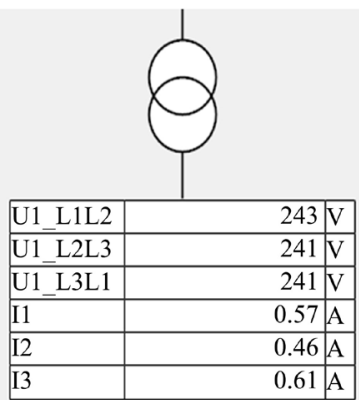

(a)

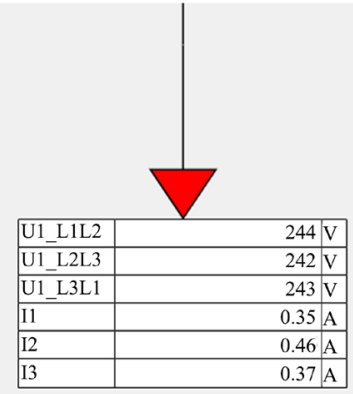

(b)

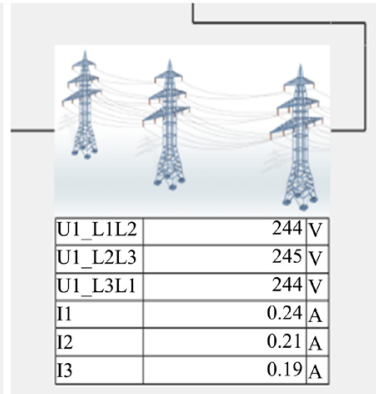

(c)

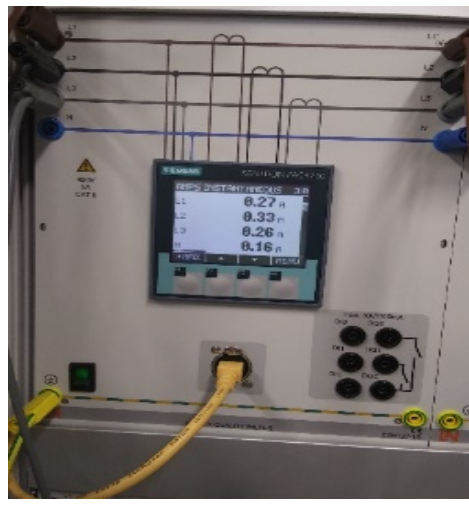

(d)

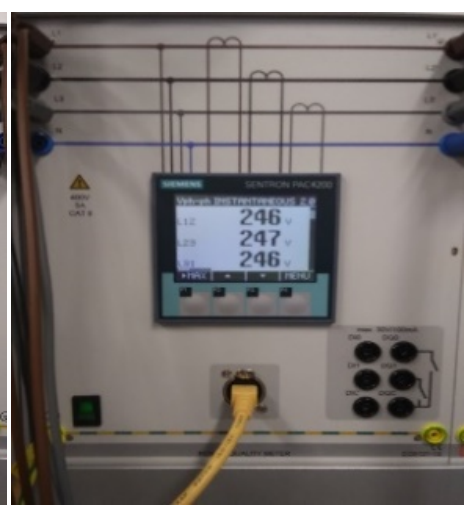

(e)

Figure 8. A three-bus system results in SCADA system. (a) Line voltage and injected current at bus 1; (b) Line voltage and injected current on bus 2; (c) Line voltage and injected current on bus 3; (d) and (e) meter measurements.

\subsection{Three Bus Test System}

The performance of the proposed method is verified on the three bus systems. In 
addition, the MATLAB code for the power dispatch without and with adding new D.G. has been run. The optimization process's stopping criteria are set as the iteration number reaching 200 iterations to give the particles enough opportunities to reach the global minimum. The size of the swarm is 50 . The initial weight inertia is set to 0.9 , and the final weight inertia is set to 0.4 . As the iterations go on, the weight value will drop from 0.9 to 0.4 . When the optimization process begins, each particle's position will be continuously updated until they reach the stopping criteria.

The results show that the minimum losses occurred when the D.G. was installed at bus no.3; it is given 15.944 MW when used the APSO technique. From this Table, we can learn that the real power loss can be reduced by $10.47 \%$; after adding a new D.G. to the system and using the APSO algorithm to further adjust the control variables' values, the real power loss can be reduced by as much as $14.42 \%$. A comparison of the loss reduction when D.G. is installed, the results also show that the losses result in each line, and the total losses for the system are close for both techniques. The losses after adding D.G. are less than the losses before installed D.G., so the power losses are modified in each line and the system due to installing a wind generator at the optimum location of bus no. 3 . The voltage magnitude and the angle are modified after installed the wind turbine at the optimum location.

Figure 9 shows the power losses when installing the wind generator located in a different bus position. Then it shows the minimum power, where when used the APSO technique, the minimum power accord when the D.G. located at bus three and the power losses of 15.944 MW. Finally, a comparison of the loss reduction when D.G. is installed on different buses is presented in Figure 10 using APSO techniques.

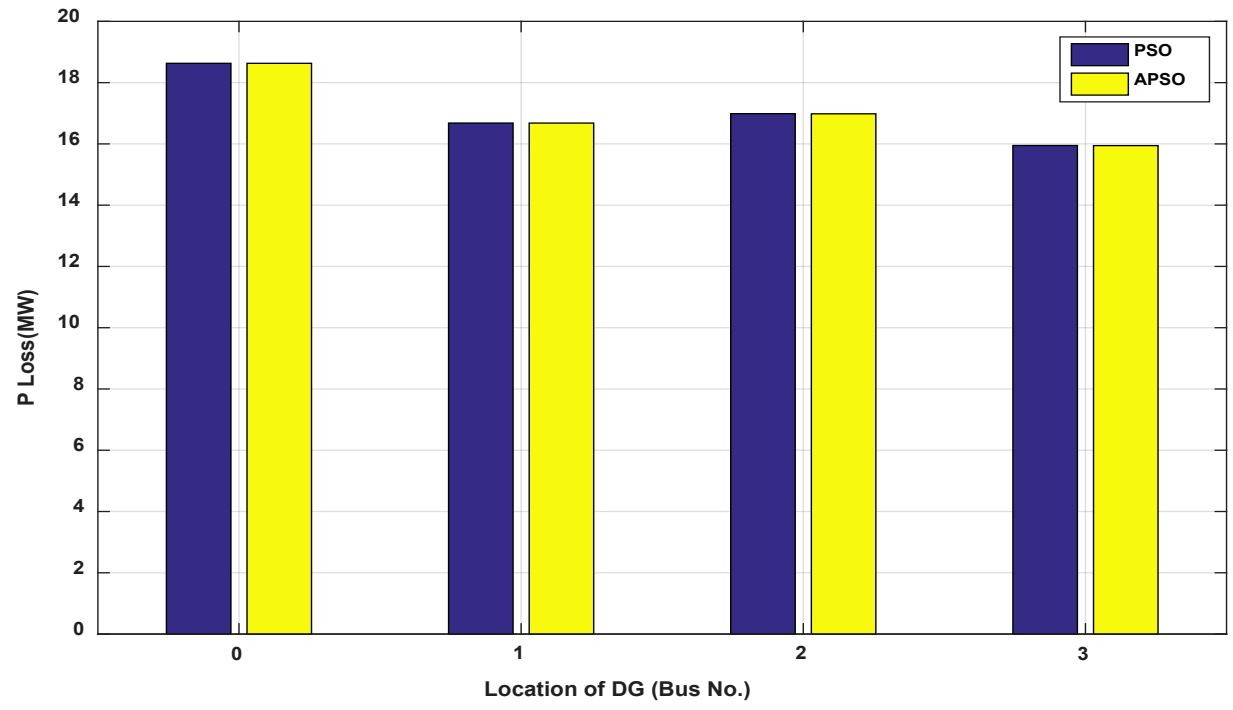

Figure 9. Active power losses when using the APSO technique when location D.G. at different busses. 
The voltage profile was evaluated using The Fast-Decoupled Load Flow (FDLF) method and then calculated the system's real power loss. After that, put wind generators at each bus to evaluate the total corresponding real power losses to obtain the D.G.'s optimal location when the total loss accord. The proposed approach is based on the APSO technique and aims to identify the load's position and compare the results with the applied standard PSO technique.

Figure 11 shows the magnitude voltage profile for different cases for APSO techniques without D.G. It compares it without optimization, and the figure illustrates the voltage magnitude improved when using optimization. As shown in Figure 12, the angle profile improved where the angle changed from $-9^{\circ}$ the $-7.2^{\circ}$ when optimization was used. In addition, the voltage magnitude and angle improved when a wind generator was installed, as shown in Figure 13 and Figure 14 , respectively.

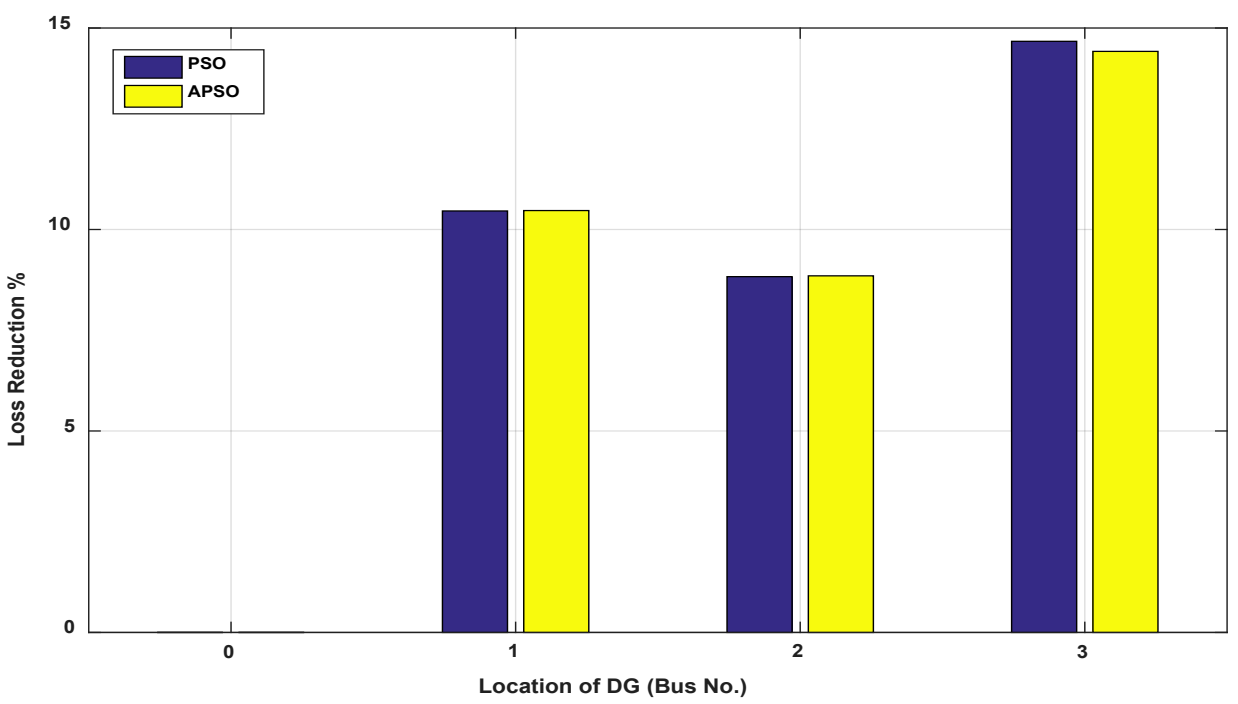

Figure 10. Percentage of active power losses reduction.

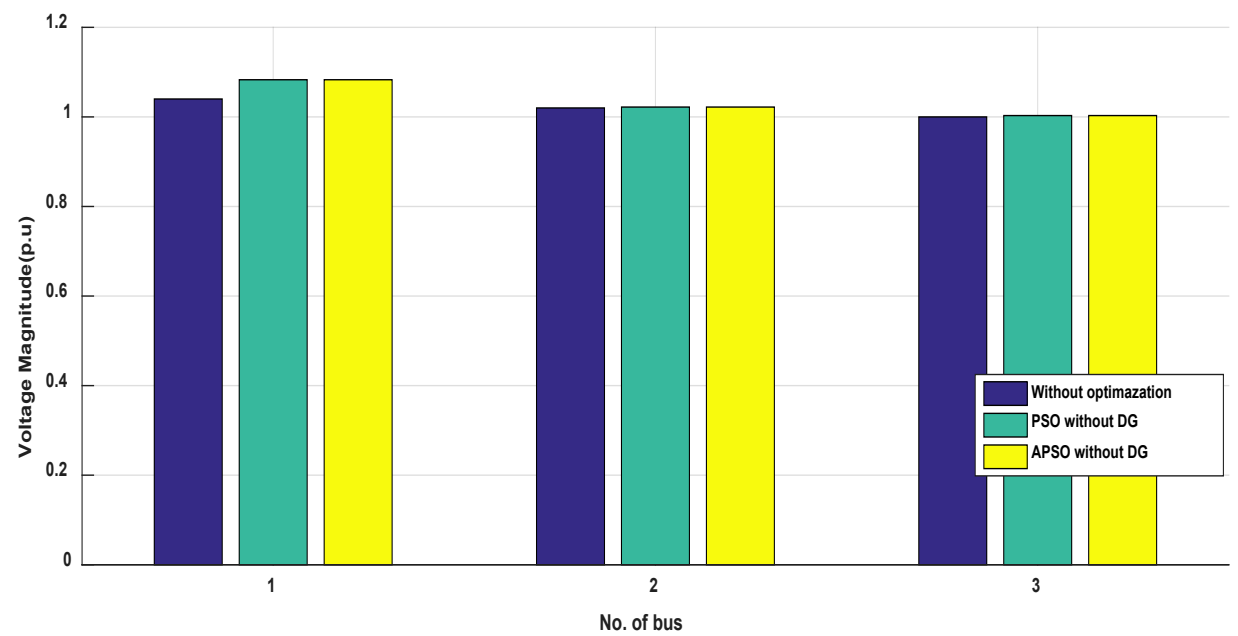

Figure 11. Voltage magnitude profile without and with optimization and without a wind turbine. 


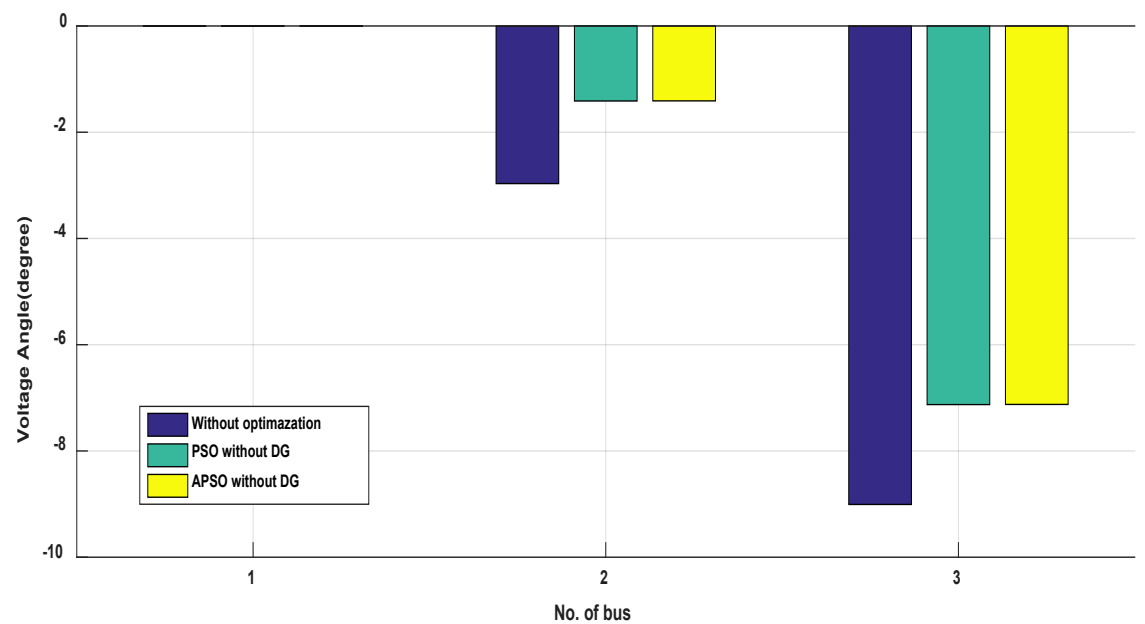

Figure 12. Voltage angle profile without and with optimization and without a wind turbine.

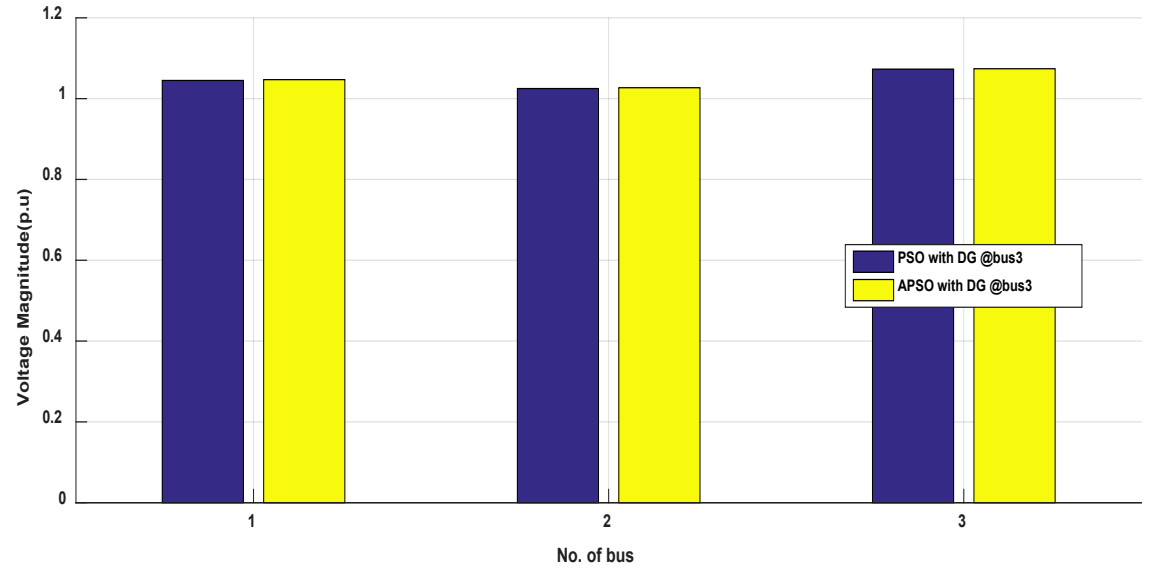

Figure 13. Voltage magnitude profile wind turbine.

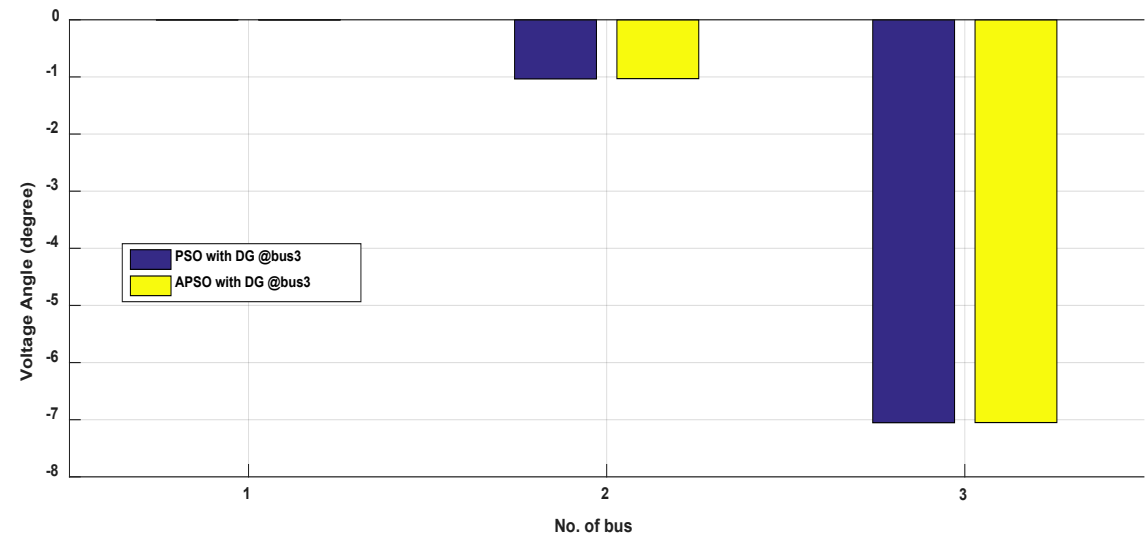

Figure 14. Voltage angle profile with wind turbine.

\section{Conclusion}

Based on the analysis and results presented in this work, the following conclu- 
sions are drawn: The comparison between two techniques is used to identification of an optimum location by using standard particle swarm optimization Technique and accelerated particle swarm optimization Technique, and the obtained results explain the affiant the APSO method when taking the consideration of iteration number, fast of execution time, reducing power losses, improve the power losses on the transmission line and improve the power flow, and improve the magnitude and angle voltage profile. A better efficiency than standard low speed wind turbines is achieved using a wind turbine. There are no ends to the development of wind turbines: Global research initiatives are underway with wind turbines of diverse capacities. The energy mix of the future cannot be anticipated properly because of the diversity of energy sources available. However, regenerative energy sources are certain to rise in importance, especially wind, and will probably substitute for fossil fuels such as coal and gas in the long term. Nevertheless, in the future, long-term energy-mix policies, which incorporate not only the environment but also economic and reliable supply, will not be enough for regenerative energy alone.

\section{Conflicts of Interest}

The authors declare no conflicts of interest regarding the publication of this paper.

\section{References}

[1] Rahman, I., Vasant, P., Singh, B. and Abdullah, M. (2016) On the Performance of Accelerated Particle Swarm Optimization for Charging Plug-In Hybrid Electric Vehicles. Alexandria Engineering Journal, 55, 419-426. https://doi.org/10.1016/j.aej.2015.11.002

[2] Zhou, W.C., Lou, Z., Lu, L. and Yang, H. (2010) Current Status of Research on the Optimum Sizing of Standalone Hybrid Solar-Wind Power Generation Systems. Applied Energy, 87, 380-389. https://doi.org/10.1016/j.apenergy.2009.08.012

[3] Okundamiya, M.S., Emagbetere, J.O. and Ogujor, E.A. (2014) Design and Control Strategy for a Hybrid Green Energy System for Mobile Telecommunication Sites. Journal of Power Sources, 257, 335-343. https://doi.org/10.1016/j.jpowsour.2014.01.121

[4] Okundamiya, M.S. and Nzeako, A.N. (2013) Model for Optimal Sizing of a Wind Energy Conversion System for Green-Mobile Applications. International Journal of Green Energy, 10, 205-218. https://doi.org/10.1080/15435075.2011.653848

[5] Okundamiya, M.S. and Omorogiuwa, O. (2016) Analysis of an Isolated Micro-Grid for Nigerian. Terrain 2016 IEEE 59th International Midwest Symposium on Circuits and Systems (MWSCAS), Abu Dhabi, 16-19 October 2016. https://doi.org/10.1109/MWSCAS.2016.7870060

[6] Ilyas, M., Tanweer, S.M. and Rahman, A. (2013) Optimal Placement of Distributed Generation on Radial Distribution System for Loss Minimisation \& Improvement of Voltage Profile. International Journal of Modern Engineering Research (IJMER), 3, 2296-2312.

[7] Shivarudraswam, R., Gaonkar, D.N. and Jayalakshmi, N.S. (2016) GA Based Optimal Location and Size of the Distributed Generators in Distribution System for Dif- 
ferent Load Conditions. 1st IEEE International Conference on Power Electronics, Intelligent Control and Energy Systems (ICPEICES), Delhi, 4-6 July 2016. https://doi.org/10.1109/ICPEICES.2016.7853256

[8] Sri Kumar, K. (2019) Optimal Size \& Location of Distributed Generation Using Bird Swarm Optimization with Cuckoo Search Sorting Algorithm. International Journal of Engineering and Advanced Technology, 8, 781-787.

https://doi.org/10.35940/ijeat.F1147.0986S319

[9] Liu, C.L., Bao, H. and Liu, H. (2011) Siting and Sizing of Distributed Generation Based on the Minimum Transmission Losses Cost. IEEE Power Engineering and Automation Conference, Wuhan, 8-9 September 2011. https://doi.org/10.1109/PEAM.2011.6135006

[10] Suresh, M.C.V. and Belwin, E.J. (2018) Optimal DG Placement for Benefit Maximization in Distribution Networks by Using the Dragonfly Algorithm. Renewables. Wind, Water, and Solar, 5, Article No. 4.

https://doi.org/10.1186/s40807-018-0050-7

[11] Ghatak, S.R. and Acharjee, P. (2016) Optimal Allocation of DG Using Exponential PSO with Reduced Search Space. Second International Conference on Computational Intelligence \& Communication Technology (CICT), Ghaziabad, 12-13 February 2016. https://doi.org/10.1109/CICT.2016.103

[12] Castillo, H.D. and Saad, M. (2017) Optimal Location and Size for Various Renewable Distributed Generators in Distribution Networks. 2017 IEEE PES Innovative Smart Grid Technologies Conference-Latin America (ISGT Latin America), Quito, 20-22 September 2017. https://doi.org/10.1109/ISGT-LA.2017.8126715

[13] Asija, D., Soni, K.M., Sinha, S.K. and Yadav, V.K. (2016) Optimal Placement of Distributed Generator for Maximum Load Allowability and Reduced Losses Were Mitigating Congestion of the Transmission System. 20167 th India International Conference on Power Electronics (IICPE), Patiala, 17-19 November 2016. https://doi.org/10.1109/IICPE.2016.8079339

[14] Abood, S. (2020) Fundamentals of Electrical Power Systems: A Primer with MATLAB. Nova, Science and Technology, Technology and Engineering, USA. https://doi.org/10.52305/QPUB7144

[15] Yang, X.S. (2008) Nature-Inspired Metaheuristic Algorithms. Luniver Press, Russian.

[16] Ali, W.H., Abood, S., Attia, J., Fuller, J. and Cofie, P. (2019) Microgrid Optimum Identification Location Using Standard and Accelerated Particle Swarm Optimization Techniques. London Journal of Engineering Research, 19.

[17] Roy, P. and Dutta, S. (2019) Optimal Power Flow Using Evolutionary Algorithms. IGI Global, Hershey. https://doi.org/10.4018/978-1-5225-6971-8

[18] Digehsara, P.A., Chegini, S.N., Bagheri, A. and Roknsaraei, M.P. (2020) An Improved Particle Swarm Optimization Based on the Reinforcement of the Population Initialization Phase by Scrambled Halton Sequence. Cogent Engineering, 7, Article ID: 1737383. https://www.tandfonline.com/loi/oaen20

[19] Al-Rubayi, R.H., Abd, M.K. and Flaih, F.M.F. (2020) A New Enhancement on PSO Algorithm for Combined Economic-Emission Load Dispatch Issues. International Journal of Intelligent Engineering and Systems, 13, 77-85. https://doi.org/10.22266/ijies2020.0229.08

[20] Wang, H. and Wang, Z.J. (2019) Multi-Objective Reactive Power Optimization Including Distributed Generation. Advances in Sciences and Engineering, 11, 46-52. https://doi.org/10.32732/ase.2019.11.1.46 
[21] Shiue, S.M., Huang, L.J., Tsai, W.H. and Chen, Y.-L. (2018) On Four Metaheuristic Applications to Speech Enhancement-Implementing Optimization Algorithms with MATLAB R2018a. Proceedings of the 30 th Conference on Computational Linguistics and Speech Processing (ROCLING 2018), Hsinchu, October 2018, 266-275.

[22] Chen, L., Chen, W., Uwe, K. and Bletzinge, W. (2020) A Gradient Descent Akin Method for Inequality Constrained Optimization.

[23] Mahmoodian, V., Charkhgard, H. and Zhang, Y. (2019) Multi-Objective Optimization Based Algorithms for Solving Mixed Integer Linear Minimum Multiplicative Programs. Computers \& Operations Research, 128, Article ID: 105178.

[24] Zhu, Y., Liu, X., Zhai, Y. and Deng, R. (2019) Monthly Unit Commitment Model and Algorithm with Renewable Energy Generation Considering System Reliability. Mathematical Problems in Engineering, 2019, Article ID: 3835296. https://doi.org/10.1155/2019/3835296

[25] Frank, S. and Rebennack, S. (2016) An Introduction to Optimal Power Flow: Theory, Formulation, and Examples. IIE Transactions, 48, 1172-1197. https://doi.org/10.1080/0740817X.2016.1189626

[26] Han, H., Hou, X., Yang, J., Wu, J., Su, M. and Guerrero, J.M. (2015) Review of Power-Sharing Control Strategies for Islanding Operation of A.C. Microgrids. IEEE Transactions on Smart Grid, 7, 200-215. https://doi.org/10.1109/TSG.2015.2434849

[27] Ahmed, G., Khalil, A., Alyami, S., Sayed, K. and Alhejji, A. (2019) Dynamic Modeling of wind Turbines Based on Estimated Wind Speed under Turbulent Conditions. Energies, 12, 1907.

[28] Simani, S. (2015) Overview of Modelling and Advanced Control Strategies for Wind Turbine Systems. Energies, 8, 13395-13418. https://doi.org/10.3390/en81212374

[29] Ragheb, M. (2017) Wind Energy Conversion Theory, Betz Equation.

[30] Astolfi, D. and Castellani, F. (2019) Wind Turbine Power Curve Upgrades: Part II. Energies, 12, 1503. https://doi.org/10.20944/preprints201804.0269.v1

[31] Abood, S. and Fayyadh, M. (2020) Advanced Power Systems and Security: Computer Aided Design. Nova, Science and Technology, Technology and Engineering, USA. https://doi.org/10.52305/BXQE5101 